\section{Evaluating imaging-pathology concordance and discordance after ultrasound-guided breast biopsy}

\author{
Vivian Youngjean Park, Eun-Kyung Kim, Hee Jung Moon, Jung Hyun Yoon, Min Jung Kim \\ Department of Radiology and Research Institute of Radiological Science, Severance Hospital, \\ Yonsei University College of Medicine, Seoul, Korea
}

Ultrasound (US)-guided breast biopsy has become the main method for diagnosing breast pathology, and it has a high diagnostic accuracy, approaching that of open surgical biopsy. However, methods for confirming adequate lesion retrieval after US-guided biopsy are relatively limited and false-negative results are unavoidable. Determining imaging-pathology concordance after US-guided biopsy is essential for validating the biopsy result and providing appropriate management. In this review article, we briefly present the results of US-guided breast biopsy; describe general aspects to consider when establishing imaging-pathology concordance; and review the various categories of imaging-pathology correlations and corresponding management strategies.

Keywords: Ultrasonography; Biopsy; Breast

\section{Introduction}

Percutaneous breast biopsy has become the foundation of diagnosing breast pathology, with most biopsies performed under imaging guidance [1]. With technological advancements in both imaging techniques and larger core biopsy devices, ultrasound (US)-guided biopsy is now widely applied to the majority of breast lesions, including microcalcifications and non-mass lesions [2-4]. The false-negative rate of 14-gauge US-guided core needle biopsy (CNB) ranges from $0.1 \%$ to $3.7 \%$, which approaches that of open surgical biopsy [1,5-11]. However, the success of an imaging-guided breast biopsy depends not only on the biopsy technique, but also on determining imaging-pathology concordance and appropriate post-biopsy management for patients after the procedure. In this article, we briefly review the published results of US-guided breast biopsy, discuss aspects to consider when establishing imagingpathology concordance, describe the possible categories of imaging-pathology correlations, and briefly discuss the appropriate post-biopsy management for each category, along with selected images.

\section{Review of US-Guided Breast Biopsy}

US-guided CNB has shown high diagnostic accuracy for the diagnosis of breast cancer. Although first described by Roberts et al. in 1975 [12], it became widely used to evaluate breast lesions after

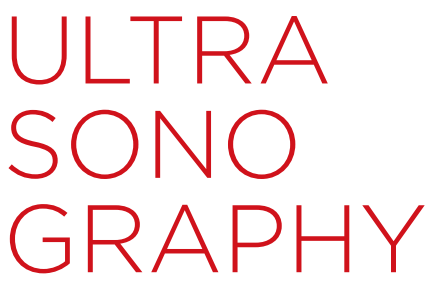

\section{REVIEW ARTICLE}

https://doi.org/10.14366/usg.17049 pISSN: 2288-5919 • elSSN: 2288-5943 Ultrasonography 2018;37:107-120

Received: June 30, 2017

Revised: August 17, 2017

Accepted: August 19, 2017

Correspondence to: Min Jung Kim, MD, PhD, Department of Radiology and Research Institute of Radiological Science, Severance Hospital, Yonsei University College of Medicine, 50-1 Yonsei-ro, Seodaemungu, Seoul 03722, Korea

Tel. +82-2-2228-7400

Fax. $+82-2-393-3035$

E-mail: mines@yuhs.ac

This is an Open Access article distributed under the terms of the Creative Commons Attribution NonCommercial License (http://creativecommons.org/ licenses/by-nc/3.0/) which permits unrestricted noncommercial use, distribution, and reproduction in any medium, provided the original work is properly cited.

Copyright @ 2018 Korean Society of Ultrasound in Medicine (KSUM)

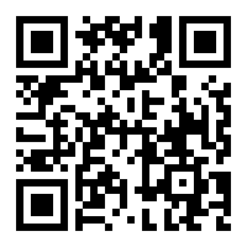

How to cite this article:

Park VY, Kim EK, Moon HJ, Yoon JH, Kim MJ. Evaluating imaging-pathology concordance and discordance after ultrasound-guided breast biopsy. Ultrasonography. 2018 Apr;37(2):107-120. 
Parker et al. first reported the use of US-guided 14-gauge CNB in $1993[1,13]$. Their initial results reported $100 \%$ agreement between needle-core and surgical diagnoses in 49 excised lesions, including 34 cancers [13]. A later study in 2005 with long-term follow-up reported a false-negative rate of $3.7 \%$ for 14 -gauge US-guided $\mathrm{CNB}$, with three delayed diagnoses of cancer occurring at the site of prior CNB [5]. However, recent studies published in the last decade have reported slightly lower false-negative rates of US-guided CNB, ranging from $0.1 \%$ to $2.5 \%$, with most cases identified because of discordance between imaging results and CNB histologic findings (Table 1) $[7-11,14,15]$. The reported underestimation rate of highrisk lesions through US-guided CNB, a category primarily composed of atypical ductal hyperplasia (ADH) lesions in most studies, ranges from $24.5 \%$ to $65 \%[7,8,10,16]$.

In the last decade, US-guided vacuum-assisted breast biopsy (VABB) has become widely practiced for both diagnostic and therapeutic purposes [17]. The reported false-negative rates for 11 -gauge or 8-gauge US-guided VABB are approximately $0.1 \%-1 \%$, and the underestimation rate of high-risk lesions is approximately $0 \%-20 \%[18-21]$. One or two missed cancers were reported in several studies on 11-gauge US-guided VABB, all of which were considered imaging-pathology discordant $[18,22,23]$. In one study, a false-negative result underwent repeat biopsy due to the progression of suspicious imaging findings [21]. In a recent study analyzing results from a 10-year period of US-guided VABB, the two false-negative results were cases performed for suspicious microcalcifications in which specimen mammography showed insufficient calcification; as such, these cases were considered imaging-pathology discordant [20].

Therefore, radiologists performing US-guided breast biopsy should be aware of the possibility of a false-negative diagnosis and be familiar with not only the biopsy technique, but how to determine imaging-pathology concordance, as well as the appropriate management strategies for patients after the procedure. In order to appropriately determine imaging-pathology concordance, it is crucial to be familiar with the Breast Imaging Reporting and Data System (BI-RADS) lexicon and classification for all available imaging modalities. In the following section, we will discuss several general aspects to consider when establishing imaging-pathology concordance after US-guided breast biopsy.

\section{Aspects to Consider When Establishing Imaging-Pathology Concordance after US-Guided Breast Biopsy}

\section{Adequate Targeting}

Although US-guided breast biopsy has an advantage over stereotactic biopsy in that targeting of the lesion can be monitored by

Table 1. Summary of false-negative results of ultrasound-guided 14-gauge core needle biopsy

\begin{tabular}{|c|c|c|c|c|c|c|}
\hline Author & $\begin{array}{c}\text { Year of } \\
\text { publication }\end{array}$ & $\begin{array}{l}\text { Patient inclusion } \\
\text { years }\end{array}$ & No. of lesions & $\begin{array}{l}\text { False-negative } \\
\text { rate }\end{array}$ & $\begin{array}{c}\text { Characteristics of } \\
\text { false-negative results }\end{array}$ & $\begin{array}{l}\text { Underestimation rate of } \\
\text { high-risk lesions }\end{array}$ \\
\hline Schueller et al. [8] & 2008 & $1995-2005$ & 1,352 & $11 / 699(1.6)$ & $\begin{array}{l}\text { Imaging-pathology discordance } \\
(n=11)\end{array}$ & 27/86 (31.4) \\
\hline \multirow[t]{4}{*}{ Youk et al. [10] } & 2008 & $2000-2005$ & 2,420 & $31 / 1,312(2.4)$ & $\begin{array}{l}\text { Imaging-pathology discordance } \\
(n=21)\end{array}$ & 25/93 (27) \\
\hline & & & & & Palpable mass $(n=3)$ & \\
\hline & & & & & Nipple discharge $(n=1)$ & \\
\hline & & & & & $\begin{array}{l}\text { Progression at ultrasonography } \\
\text { follow-up }(n=6)\end{array}$ & \\
\hline \multirow[t]{4}{*}{ Youk et al. [9] } & 2010 & $2000-2007$ & 3,724 & $50 / 1,982(2.5)$ & $\begin{array}{l}\text { Imaging-pathology discordance } \\
(n=34)\end{array}$ & $41 / 127(32.3)$ \\
\hline & & & & & Palpable mass $(n=12)$ & \\
\hline & & & & & Nipple discharge $(n=1)$ & \\
\hline & & & & & $\begin{array}{l}\text { Progression at ultrasonography } \\
\text { follow-up }(n=3)\end{array}$ & \\
\hline Zhang et al. [11] & 2012 & $2005-2011$ & 1,388 & 2/1,388 (0.1) & $\begin{array}{l}\text { Imaging-pathology discordance } \\
(n=2)\end{array}$ & N/A \\
\hline \multirow[t]{2}{*}{ Jung et al. [14] } & 2017 & $2005-2012$ & 9,068 & $63 / 3,067(2.0)$ & $\begin{array}{l}\text { Imaging-pathology discordance } \\
(\mathrm{n}=58)\end{array}$ & $79 / 322(24.5)$ \\
\hline & & & & & $\begin{array}{l}\text { Progression at ultrasonography } \\
\text { follow-up }(n=5)\end{array}$ & \\
\hline
\end{tabular}

N/A, not available. 
real-time needle visualization, the methods for confirming adequate tissue sampling are relatively limited. Specimen mammography cannot be applied as a confirmation method for tissue retrieval from breast lesions without suspicious microcalcifications, and therefore real-time evaluation of the needle position is very important. The radiologist must be aware of any technical difficulties that can cause targeting errors secondary to poor needle or lesion visualization, deep lesions, mobile lesions, or dense tissue that is difficult to traverse [24]. During the procedure, obtaining post-fire needle position verification by obtaining US images that show the entire length of the needle passing through the target lesion are important for assuring that adequate targeting was achieved (Fig. 1). For small lesions, US images may appear as if the needle is within a lesion when it is actually adjacent to the lesion, and additionally obtaining post-fire images in the orthogonal plane can help evaluate the needle position more precisely [25].

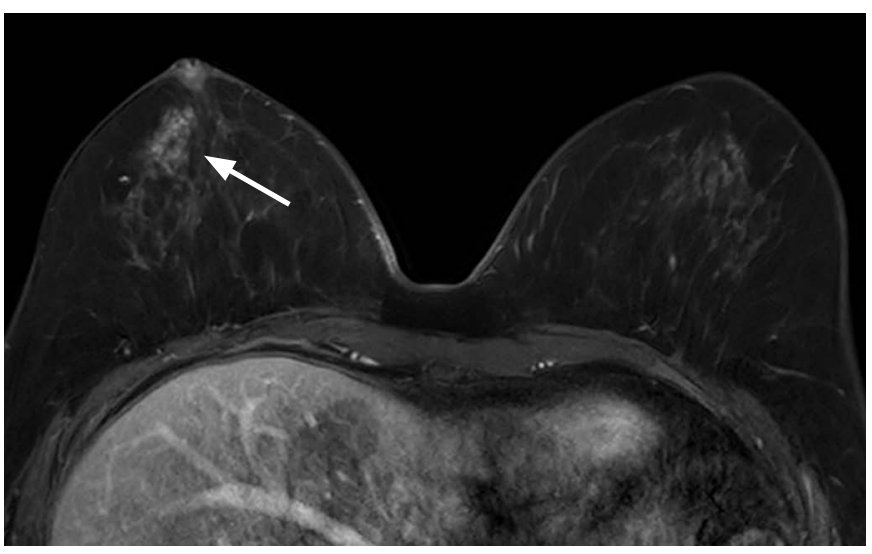

A

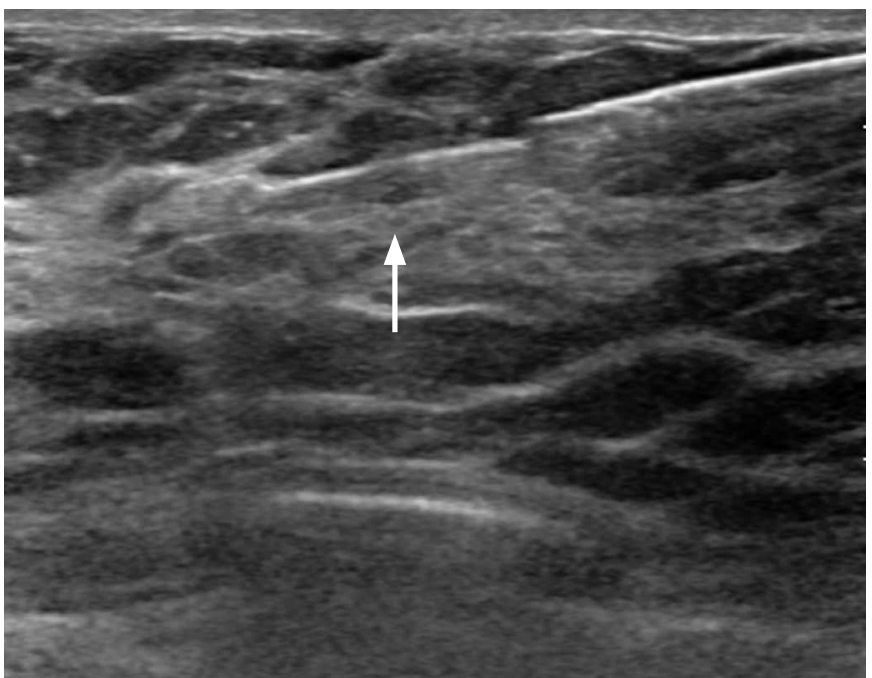

C

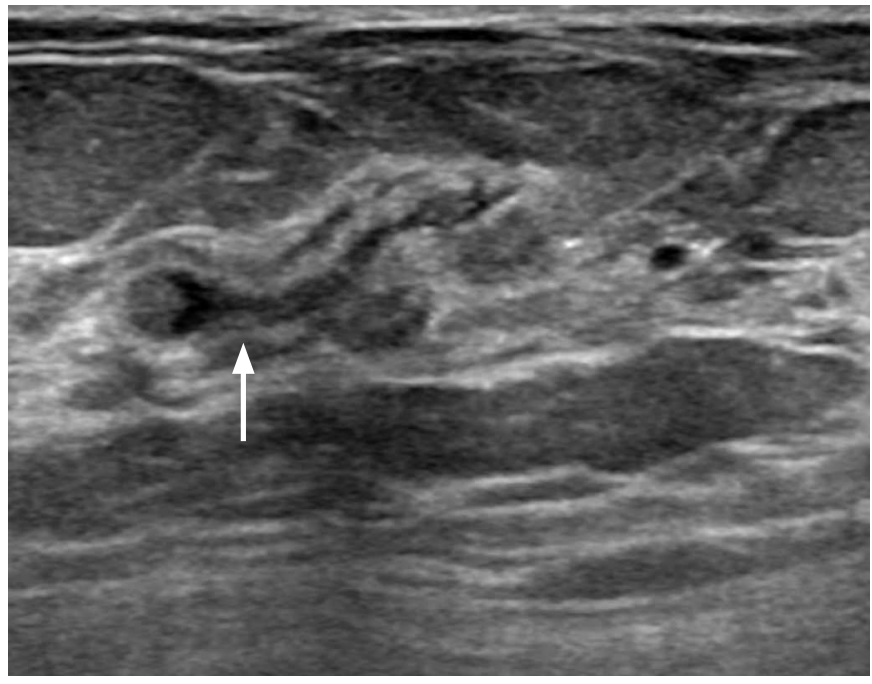

B

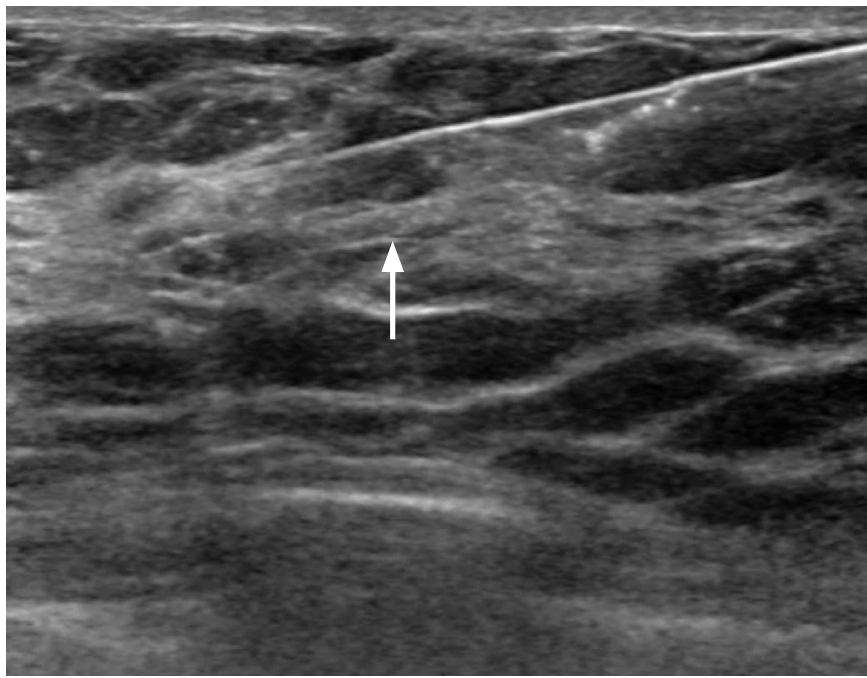

D

Fig. 1. A 73-year-old woman with known breast cancer who underwent targeted ultrasonography (US) for an additional suspicious lesion on breast magnetic resonance (MR) imaging.

A. Axial early dynamic contrast-enhanced MR shows segmental non-mass enhancement (arrow) in the right outer central breast. B. Targeted US shows segmental ductal dilatation with an isoechoic intraductal lesion (arrow) in the right outer central breast, correlated with the nonmass enhancement on MR images. C, D. Pre- (C) and post-fire US (D) during US-guided core needle biopsy (CNB) show that the needle passed through the subcutaneous fat layer anterior to the target (arrow), failing to sample the right outer central breast lesion. The CNB result was fibroadipose tissue, and the final surgical pathological result following US-guided localization was intraductal papilloma. 


\section{Adequate Sampling}

Although image-guided percutaneous breast biopsies are an accurate alternative to excisional biopsy, sampling error is a major possible limitation and can result in a false-negative diagnosis or histologic underestimation. In a validation study of 1,352 14-gauge US-guided CNB cases, in all 11 false-negative cases, the most suspicious areas of each lesion were missed by the needle, and the lesions were considered imaging-pathology discordant [8]. It is important to be familiar with the BI-RADS classification for all available imaging modalities, and to sample the most suspicious

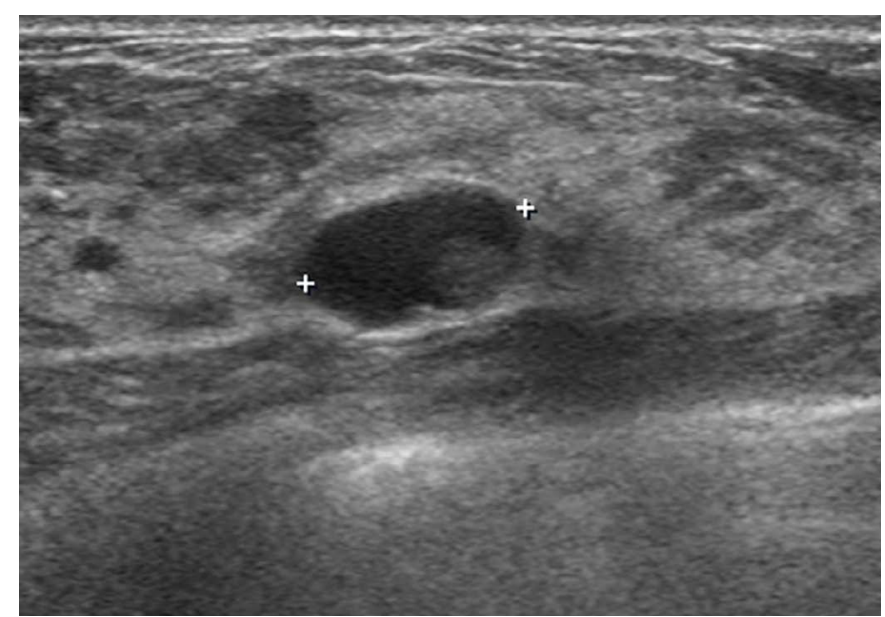

A

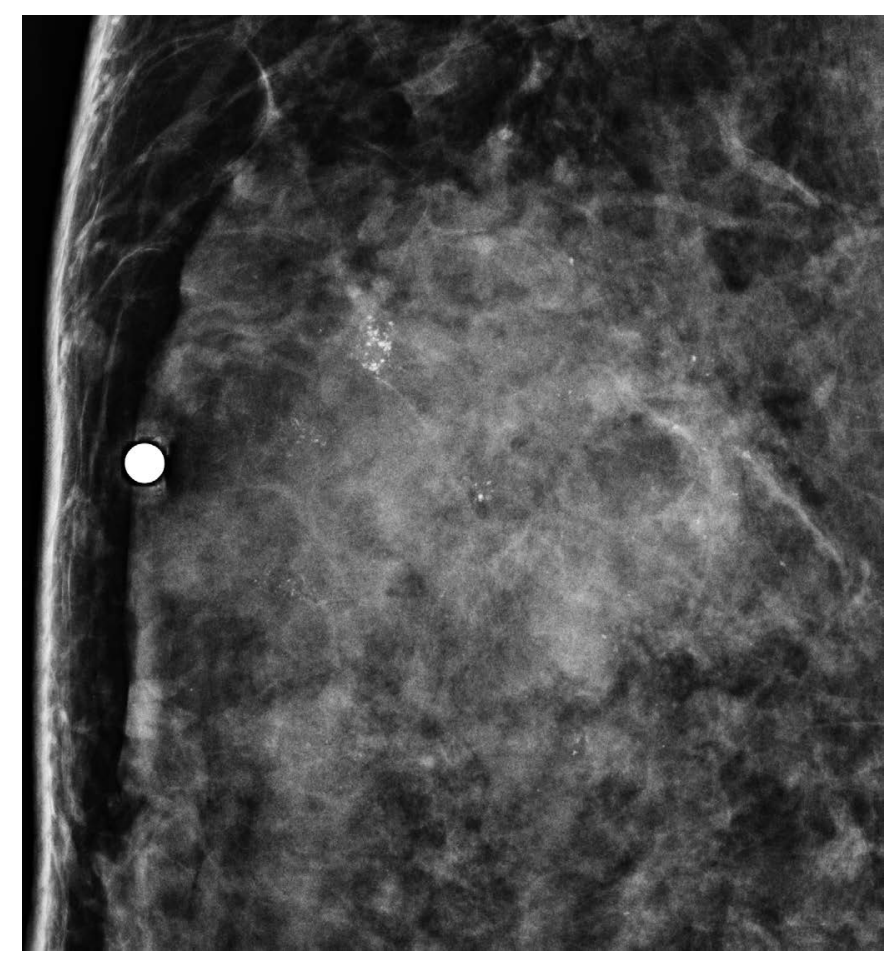

area seen on imaging (Fig. 2). The number and quality of specimens have also been associated with a reliable histological diagnosis. Studies have shown that a minimum of four to five cores are necessary to obtain a definitive diagnosis with US-guided CNB, but lesions with calcifications may require more samples $[6,8,23,25,26]$. An intact specimen that has $>1 \mathrm{~cm}$ of uninterrupted length and sinks to the bottom when put into saline suggests adequate sampling and is correlated with diagnostic yield [25].

US-guided breast biopsy can be performed for suspicious microcalcifications detected on US and has advantages over

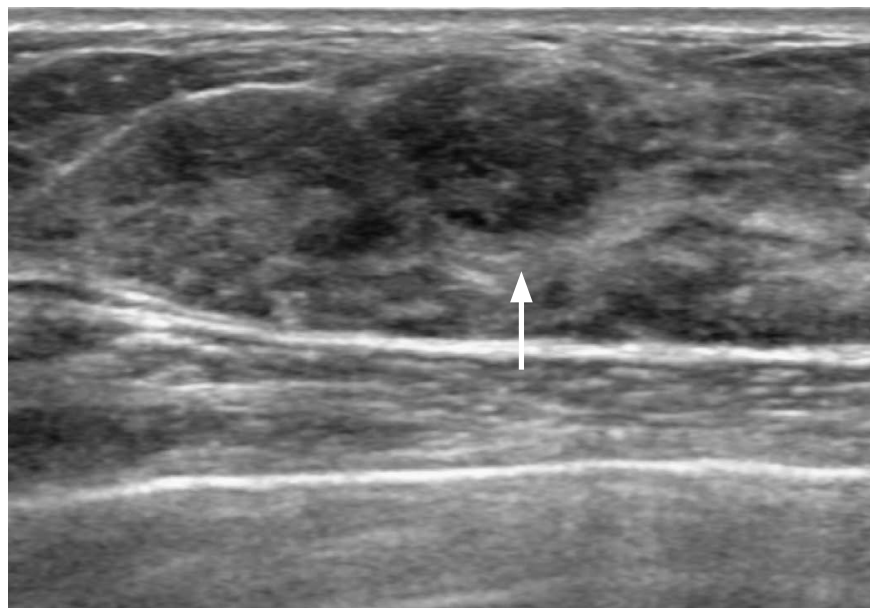

B

Fig. 2. A 42-year-old woman who was originally referred for excision of biopsy-proven intraductal papilloma.

A. Ultrasonography obtained at an outside institution shows a complex cystic and solid mass in the right upper central breast. The biopsy result was intraductal papilloma, and the patient was referred to our institution for surgical excision. B. Ultrasonography performed at our institution shows an irregular mass (arrow) at the same quadrant, with a surrounding non-mass lesion. C. Spot magnification view that was taken after placing a metallic skin marker at the suspicious mass shows that it correlated with a mass containing suspicious microcalcifications. The biopsy result of this area was ductal carcinoma in situ, and the final surgical pathological result was invasive ductal carcinoma. 
stereotactic biopsy, including improved patient comfort, no breast compression or ionizing radiation, real-time visualization of needle placement, shorter procedure time, and lower cost [2]. Placing a metallic marker on the skin over the target lesion and performing mammography prior to biopsy can ensure correlations between the microcalcifications seen on mammography and the lesion seen in US. Calcified lesions are the main cause for histologic underestimation and false-negative results in 14-gauge US-guided CNB, due to discontinuity and histologic heterogeneity [21]. US-guided VABB is more accurate than 14-gauge CNB for the evaluation of suspicious microcalcifications detected on US, and successful calcification retrieval has been reported to be more frequent for lesions associated with masses or ductal dilatation on US located at the anterior or middle portion of the breast, and to be related to lesion size, distribution, and level of suspicion based on mammography $[2,27]$. In addition, non-mass lesions on US have shown lower agreement between US- guided CNB and the surgical histological diagnosis than mass lesions [28]. Therefore, US-guided VABB may be more appropriate than 14-gauge CNB for the evaluation of suspicious microcalcifications or non-mass lesions seen on US $[2,3]$. When performing US-guided breast biopsy for microcalcifications, it is essential to obtain specimen mammography and ensure that the targeted microcalcifications are identified in the histologic specimen (Fig. 3).

\section{BI-RADS Final Assessment Category}

Since the 2003 edition of the BI-RADS was published, the BI-RADS lexicon and classification have proven to be useful for predicting the likelihood of malignancy in sonographically assessed breast lesions [29-31]. Each BI-RADS assessment category indicates an anticipated likelihood of malignancy, which is based on a thorough evaluation of the imaging features.

Category 3 (probably benign) is reserved for specific imaging

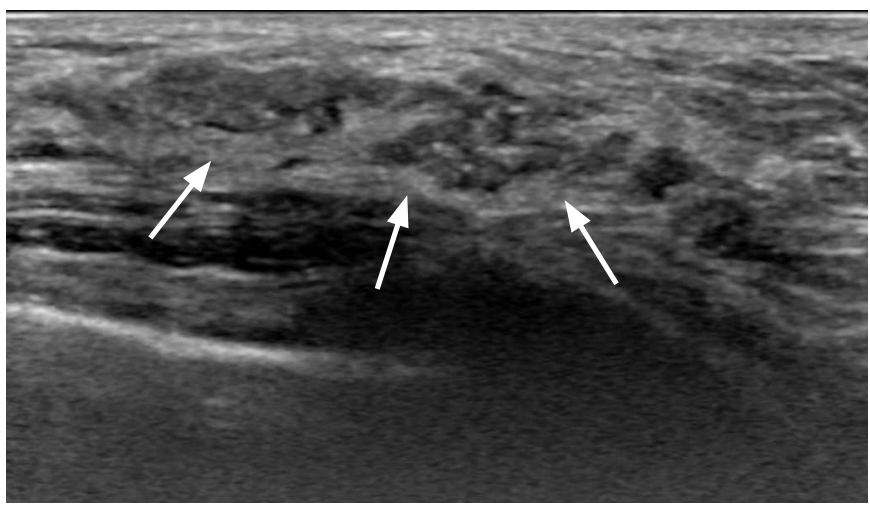

A

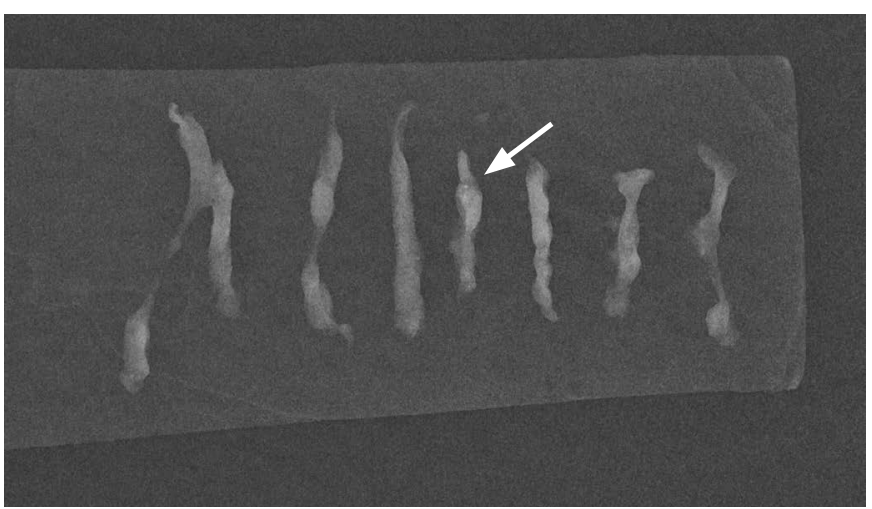

C

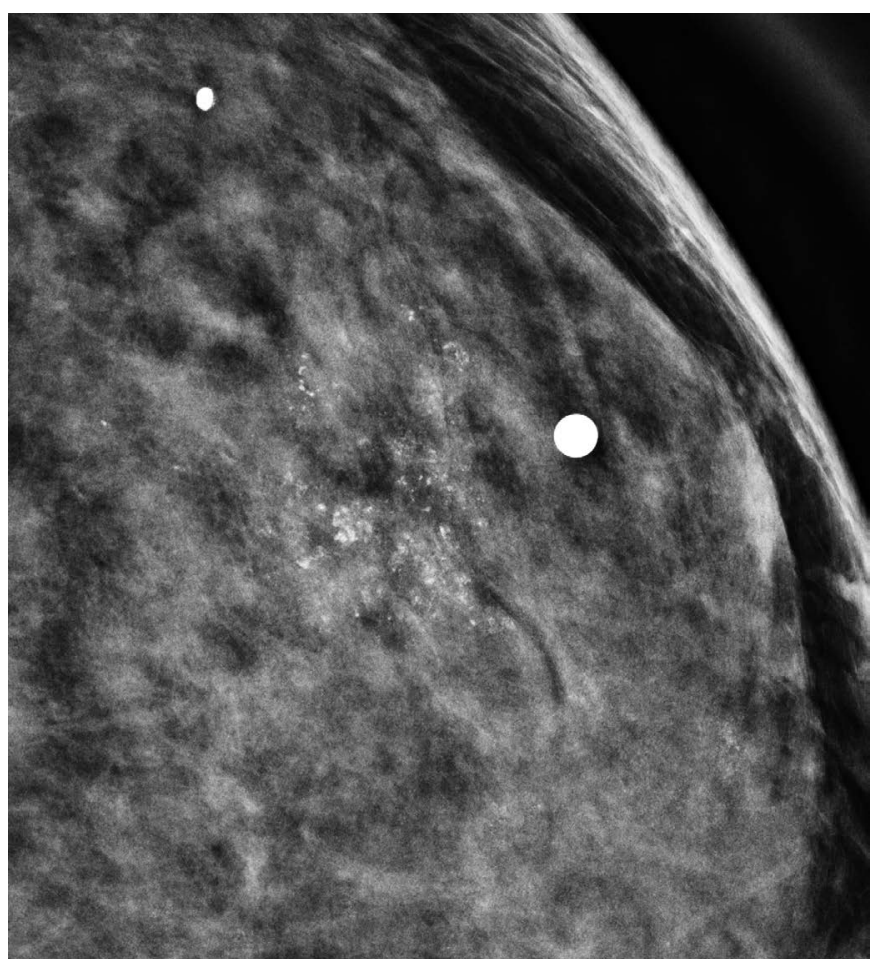

B

Fig. 3. A 43-year-old woman with suspicious calcifications on mammography.

A. Ultrasonography shows an isoechoic non-mass lesion containing tiny hyperechoic foci in the left lower outer breast (arrows). A metallic skin marker was positioned on the skin overlying this area. B. Spot magnification view shows suspicious fine pleomorphic calcifications at the area of the metallic skin marker. C. Specimen mammogram obtained after 14-gauge ultrasound-guided core needle biopsy shows that only one faint microcalcification (arrow) was retrieved, suggesting poor tissue sampling. The biopsy result was atypical ductal hyperplasia, and the final surgical pathological result was invasive ductal carcinoma. 
findings known to have a likelihood of malignancy $>0 \%$ but $\leq 2 \%$. Such lesions include solid masses with a circumscribed margin, oval shape, and parallel orientation; complicated cysts; and clustered microcysts [32]. The use of assessment category 3 for other sonographic findings can be considered only if the radiologist has personal experience suggesting a likelihood of malignancy within the defined $(\leq 2 \%)$ probably benign range. Although the recommended management is imaging follow-up, biopsy can be performed in specific circumstances, such as patient or physician preference. For category 3 lesions, a benign biopsy result can be regarded as concordant. Malignant biopsy results are considered discordant, but the sonographic features should be reviewed for subtle suspicious imaging features that can be overlooked [33].

Category 4 (suspicious) covers a wide range of likelihood of malignancy, ranging from $2 \%$ to $95 \%$. Thus, almost all recommendations for image-guided breast interventions come from assessments made using this category. Starting in the fourth edition of BI-RADS and maintained in its recent fifth edition, category 4

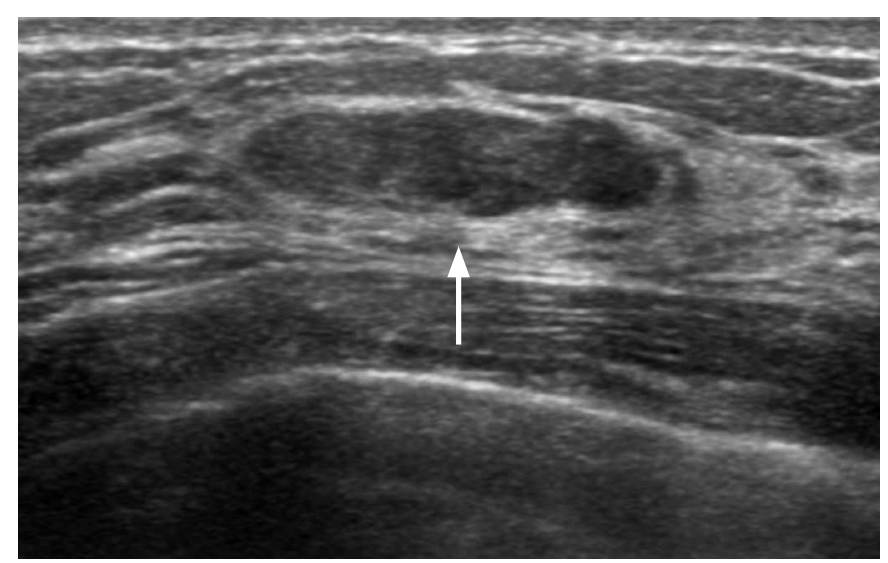

A

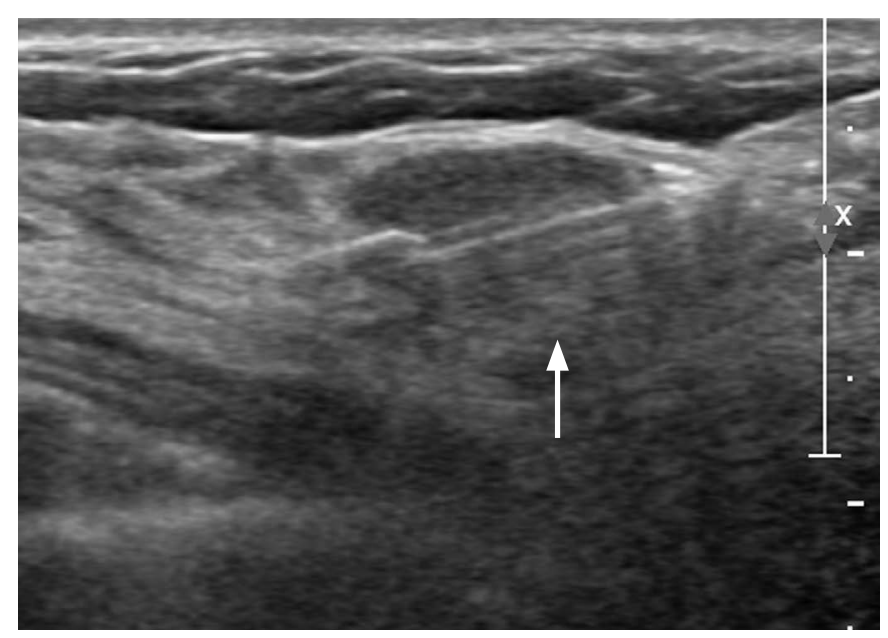

B is subdivided into $4 A, 4 B$, and $4 C$ [32]. The guidance range of the likelihood of malignancy is $>2 \%$ and $\leq 10 \%$ for category $4 A$, $>10 \%$ and $\leq 50 \%$ for category $4 \mathrm{~B}$, and $>50 \%$ and $<95 \%$ for category $4 \mathrm{C}$. Although the subcategorization of sonographic BI-RADS category 4 has been reported to be useful in predicting the likelihood of malignancy, established objective criteria do not exist for subcategorization within category 4 , and interobserver agreement has been shown to be poor [29,31,34-36]. Generally, for category $4 \mathrm{~A}$ lesions, a benign core biopsy result would be considered concordant. For category $4 \mathrm{C}$ lesions, a benign core biopsy result would more often be regarded as discordant, whereas a malignant core biopsy result would be considered concordant. For category $4 \mathrm{~B}$ lesions, a thorough review of imaging features and close imagingpathology correlation is required. In the long term, periodically performing internal audits would allow each radiologist to assess his or her overall performance and ultimately aid in determining imaging-pathology concordance.

Category 5 (highly suggestive of malignancy) carries a very high

Fig. 4. A 42-year-old woman with a mass in her left breast.

A. Ultrasonography shows a 2-cm oval circumscribed mass (arrow) in the left inner central breast, which was assessed as Breast Imaging Reporting and Data System category 3. B. Ultrasoundguided 14-gauge core needle biopsy was performed at the request of the patient, and the needle passed through the center of the mass (arrow). The biopsy result was fibrocystic change. C. Three years later, the patient returned, complaining of a new lump at the same site. Ultrasonography shows that the mass (arrow) had grown and was approximately $4 \mathrm{~cm}$ in diameter. The surgical pathological result was fibroadenoma with pseudoangiomatous stromal hyperplasia.

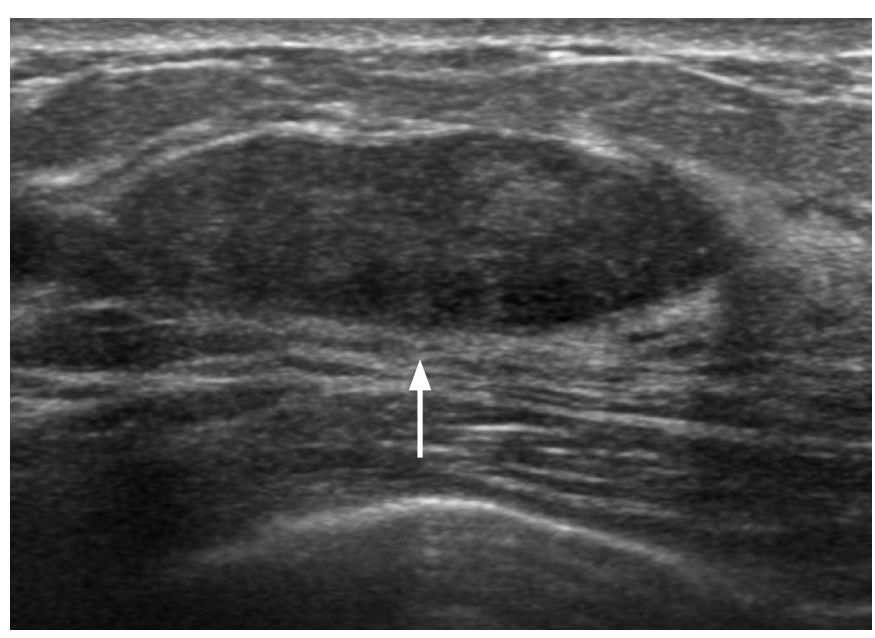

C 
probability ( $295 \%$ ) of malignancy, and any benign percutaneous tissue diagnosis should be considered discordant.

\section{Whether Pathology Results Can Explain Imaging Findings} In addition to the benignity or malignancy of biopsy results, another aspect to consider when establishing imaging-pathology concordance is whether the histologic results provide an acceptable explanation for the imaging findings. Cases with discordant pathology and imaging diagnoses can be classified as discordant, even if both imply a benign disease process [37]. According to the imaging and pathology findings, larger tissue sampling such

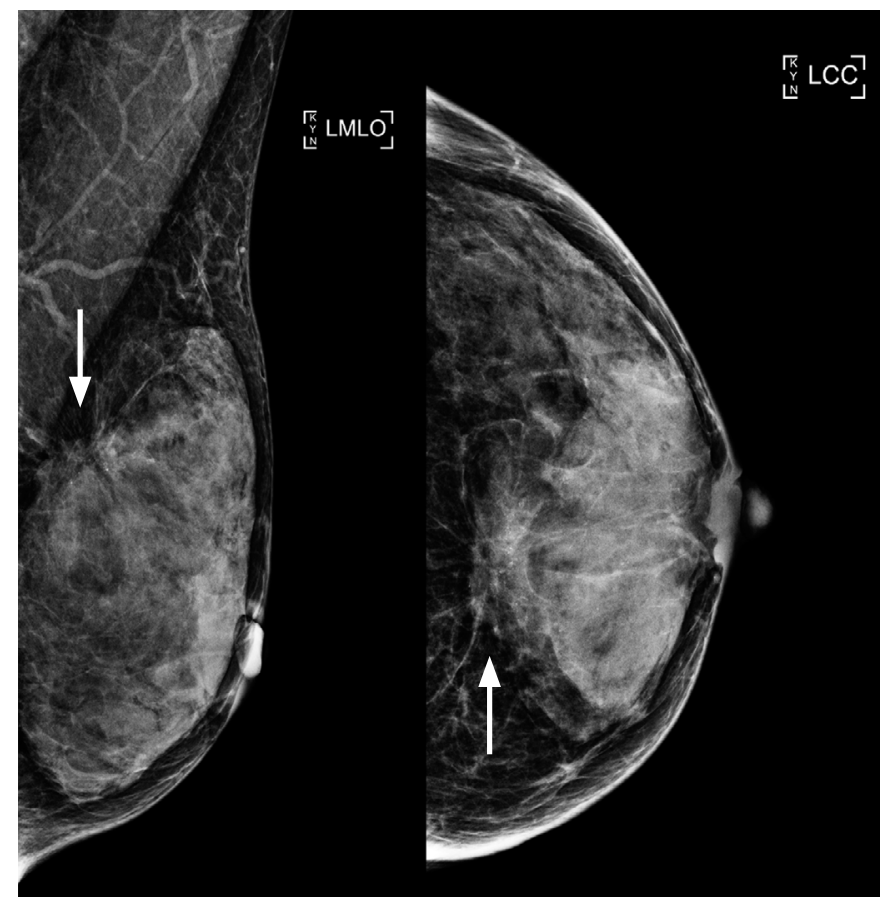

Fig. 5. A 53-year-old woman with a palpable mass in her left breast.

A. Mammography (left, mediolateral oblique view; right, craniocaudal view) shows an irregular mass with distortion (arrows) corresponding to the area of palpability. B. Ultrasonography (left, transverse view; right, longitudinal view) shows an irregular, nonparallel hypoechoic mass containing calcifications (arrows). The result of ultrasound-guided 14-gauge core needle biopsy was invasive ductal carcinoma, which was considered a concordant malignancy.

A

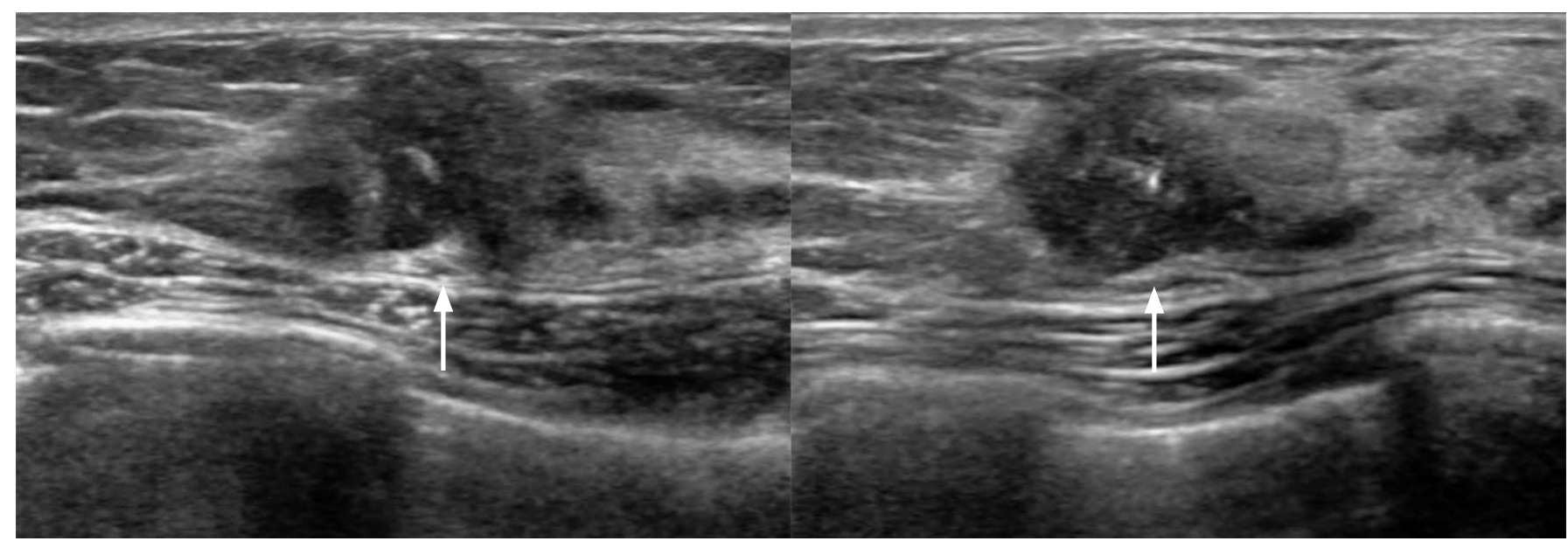

B 
fibroma, pseudoangiomatous stromal hyperplasia, and so forth [38,39]. Benign nonspecific diagnoses include fibrocystic changes, apocrine metaplasia, fibrous mastopathy, duct hyperplasia, and stromal fibrosis [38].

\section{Categories of Imaging-Pathology Concordance}

Parikh and Tickman [40] first described five possible case scenarios of imaging-pathology correlation, which are described in detail in the following section.

\section{Concordant Malignancy}

In this category, a lesion that shows imaging features suspicious

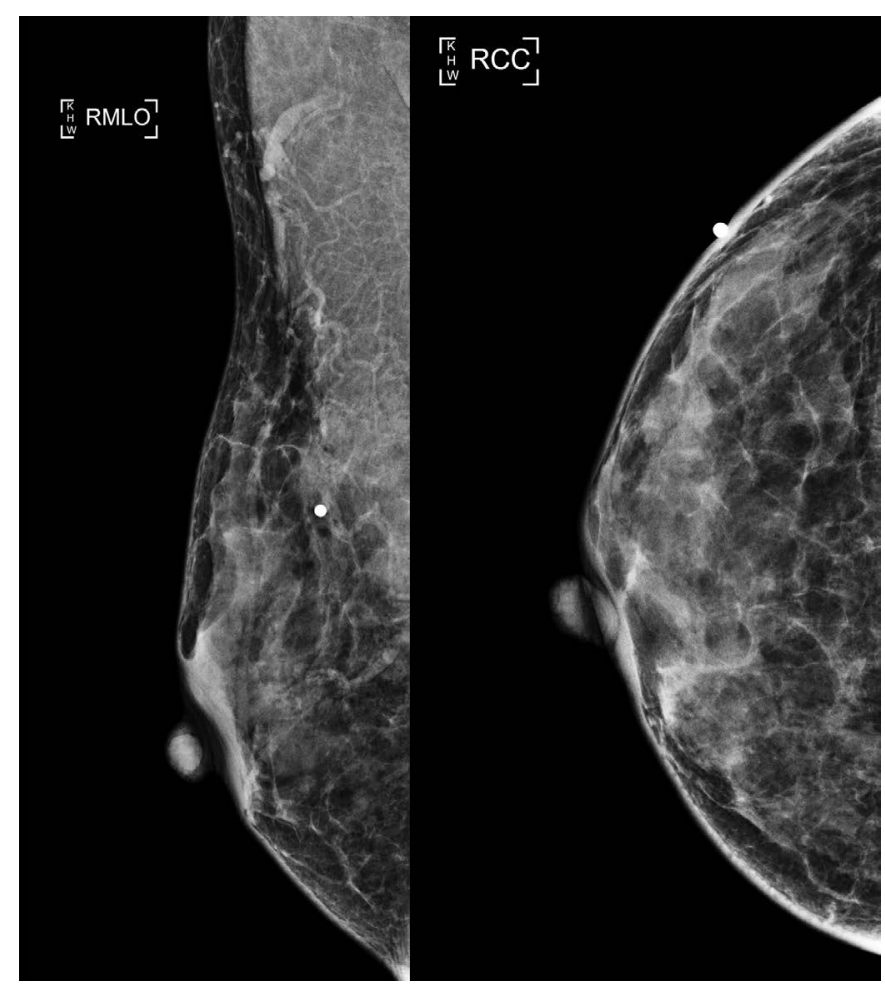

A

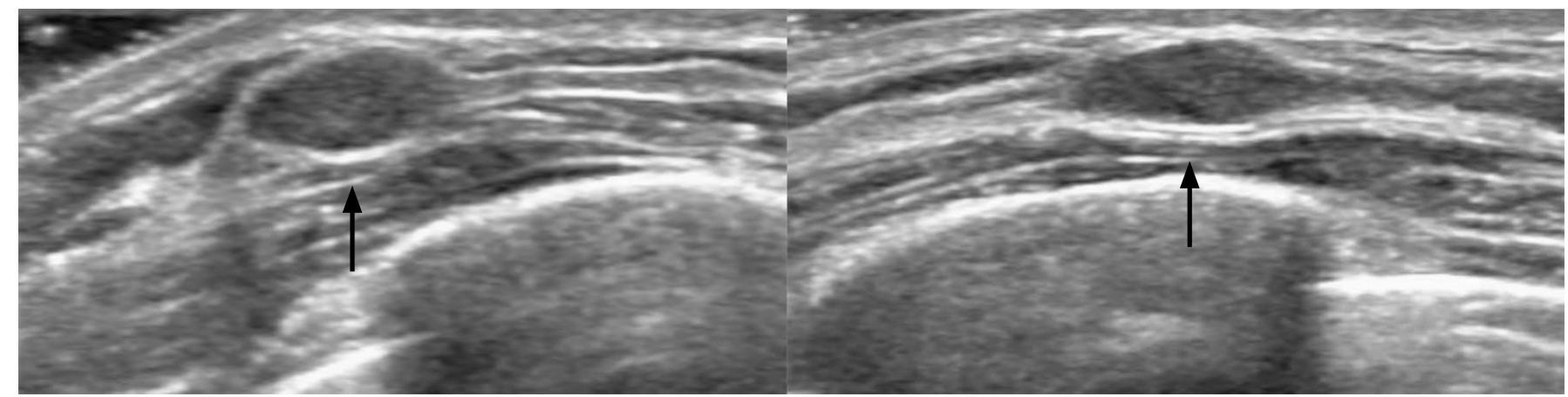

B

Fig. 6. A 58-year-old woman with a palpable mass in her right breast.

A. Mammography (left, mediolateral view; right, craniocaudal view) shows no abnormality in the palpable right upper outer breast, where a metallic skin marker was placed. B. Ultrasonography (left, transverse view; right, longitudinal view) shows an oval, parallel, and circumscribed isoechoic palpable mass (arrows). The mass was classified as Breast Imaging Reporting and Data System category 3, but ultrasound-guided 14-gauge core needle biopsy was performed at the request of the patient. The biopsy result was invasive carcinoma with micropapillary features, which was considered a discordant malignancy. The final surgical pathological result was invasive micropapillary carcinoma. for malignancy (i.e., BI-RADS category 4 or 5 ) is diagnosed as a malignancy on percutaneous biopsy. A typical example would be a spiculated mass seen on US that is diagnosed as invasive ductal carcinoma (Fig. 5). Appropriate action should be taken without delay. The radiologist should communicate the results to the referring physician, and the patient should be informed of the results

\section{Discordant Malignancy}

2 or 3) but is diagnosed as a malignancy on percutaneous biopsy falls into this category (Fig. 6). The management should be identical to that of concordant malignancy, without any delay. Malignant 
breast lesions that usually manifest as well-circumscribed masses include triple-negative or high nuclear-grade invasive ductal carcinomas not otherwise specified, metastatic lesions, lymphoma, and special-type tumors such as papillary carcinoma, mucinous carcinoma, medullary carcinoma, and metaplastic carcinoma [41,42]. The radiologist should also alert the pathologist to review and confirm the diagnosis to ensure that no interpretative or clerical errors account for the discrepancy. The images of the lesion should be reviewed thoroughly for image quality, imaging characteristics, and any missed features that might have caused underestimation in assessment.

\section{Concordant Benign}

A lesion with imaging features initially thought to be benign or likely benign (i.e., BI-RADS category 2, 3, or 4A) that also demonstrates benign pathology on percutaneous biopsy falls into this category (Fig. 7) [33]. Benign concordant results make up the majority of percutaneous breast biopsies $[43,44]$. Although this result can offer reassurance to both the physician and patient, follow-up imaging is necessary to confirm stability and to ensure the early detection of any possible missed cancers. However, the follow-up interval for benign biopsy findings with imaging-pathology concordance varies according to institution and is a matter of debate [45].

A common follow-up protocol is to perform short-interval followup imaging at 6 months after biopsy, and then annually for at least 24 months [46]. Others have suggested that follow-up intervals should be based on biopsy results, and recommend 6-month follow-up for nonspecific results and annual screening for specific benign diagnoses [47]. The reported percentage of missed cancers among concordant benign results using 14-gauge US-guided CNB ranges from $0 \%$ to $0.8 \%[5,8,9,48]$. One study reported 3 delayed diagnoses of cancer at the site of prior CNB, which showed interval growth of 16, 23, and 27 months on follow-up US [5]. Another study reported 1 false-negative case diagnosed at a 6-month follow-up US because of interval growth [48]. In the last decade, a number of studies investigating the utility of short-interval followup after benign concordant core needle breast biopsy results have been published. In one study, three missed cancers, all of which were palpable, among 1,492 lesions exhibited interval growth and were diagnosed at a 6-month follow-up [49]. In another study, two missed cancers among 1,147 lesions showed growth at a 6-month follow-up [38]. A review of the images revealed that one lesion was highly suspicious for malignancy and should had been regarded as imaging-pathology discordant, and that the other lesion had been biopsied for calcifications, but no calcifications were seen on the specimen radiograph. All other studies have reported that no malignancies were detected at the biopsy site during shortinterval follow-up $[39,43,50-53]$. Therefore, annual screening may be a reasonable follow-up protocol for benign concordant breast lesions assessed using US-guided CNB, provided that good imagingpathology correlation has been achieved.

\section{Discordant Benign}

A lesion in this category has imaging features suspicious for malignancy (i.e., BI-RADS category 4 or 5), but demonstrates benign pathology on percutaneous breast biopsy (Fig. 8). The reported percentages of imaging-pathology discordant lesions among breast CNB range from $2.0 \%$ to $19.2 \%[9,37,54-56]$. Benign lesions with spiculated findings can mimic malignancy on US, including granular cell tumor, sclerosing adenosis, postsurgical scar, fat

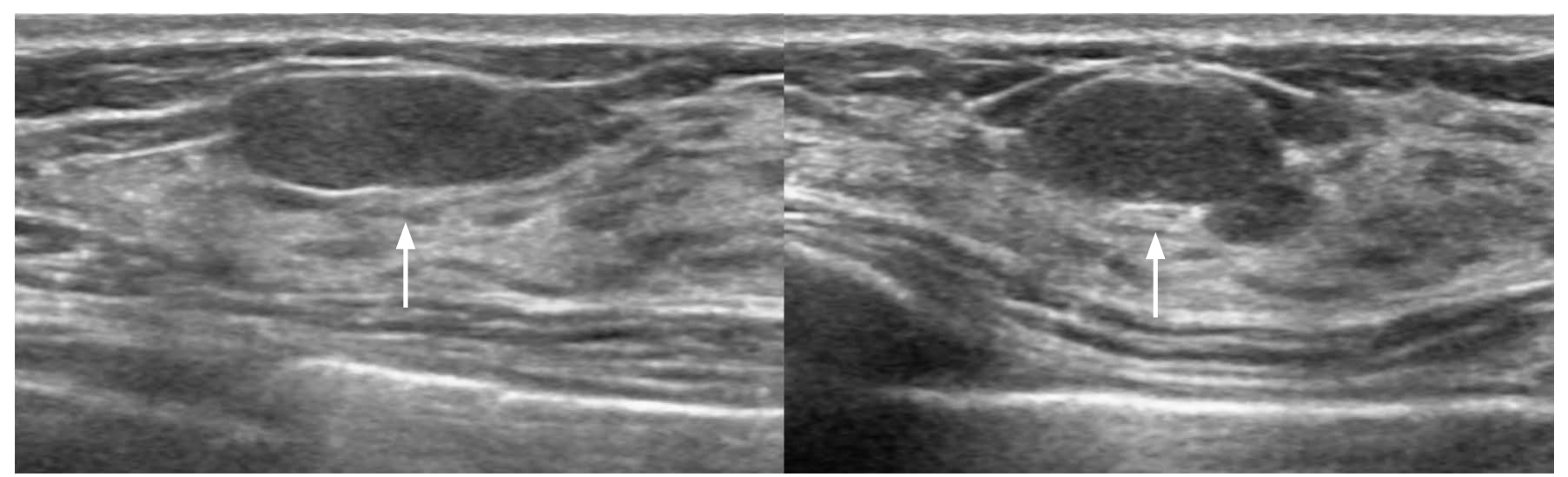

Fig. 7. A 24-year-old woman with a mass in her left breast. Ultrasonography (left, transverse view; right, longitudinal view) shows an oval circumscribed mass (arrows) in the palpable area of the left inner central breast. Ultrasound-guided 14-gauge core needle biopsy was performed at the request of the patient. The biopsy result was fibroadenoma, which was considered a concordant benign result. Subsequent vacuum-assisted biopsy also revealed fibroadenoma. 
necrosis, mastitis, diabetic mastopathy, and sarcoidosis $[33,57,58]$. However, approximately $4 \%-30.9 \%$ of discordant lesions after USguided CNB are confirmed as cancer by subsequent surgical excision $[9,37,54-56]$. If there is concern regarding a discordant benign core biopsy, it is prudent for the radiologist to immediately contact the interpreting pathologist and communicate about the discrepancy. Based on that discussion, the radiologist should communicate with the referring physician or patient and discuss the need for a repeat biopsy. In addition to surgical biopsy, US-guided VABB has been shown to be a valuable alternative to surgical biopsy for breast lesions with imaging-pathology discordance, and the reported upgrade rate ranges from $4.6 \%$ to $22.7 \%$ (Fig. 9) [54,5961]. Therefore, both surgical biopsy and US-guided VABB can be

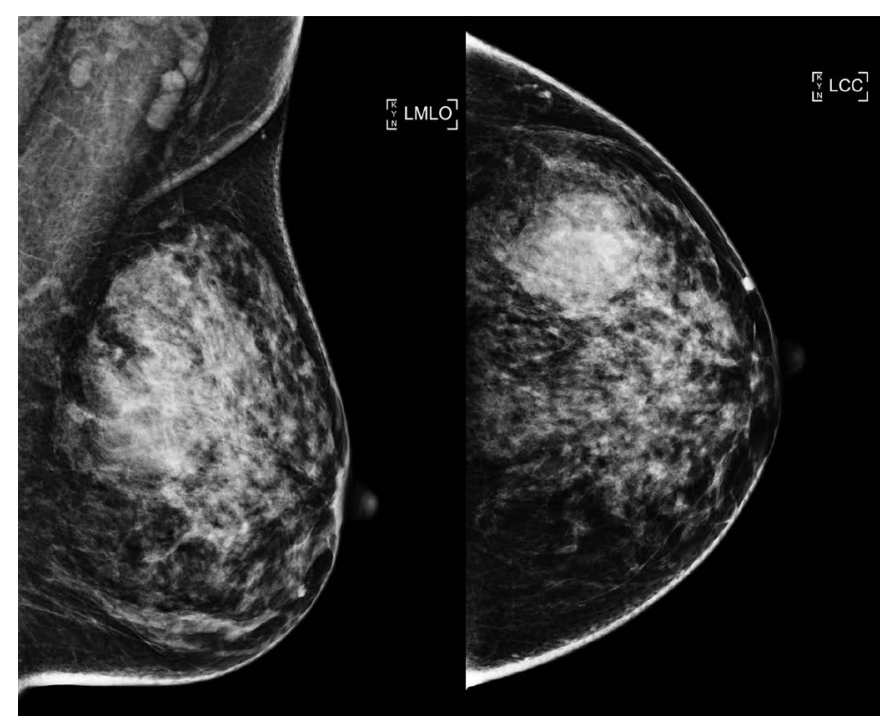

A

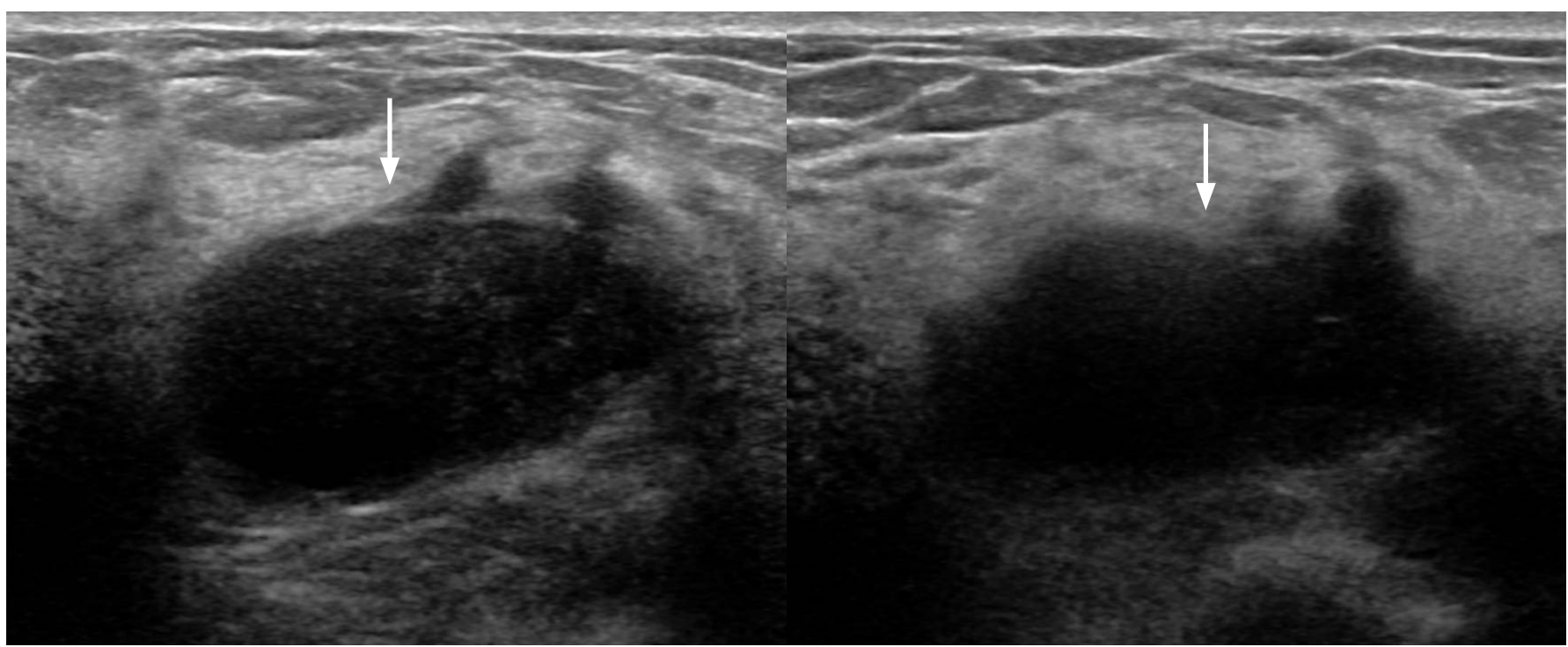

B

Fig. 8. A 51-year-old woman with a palpable mass in her left breast.

A. Mammography (left, mediolateral view; right, craniocaudal view) shows a hyperdense mass (arrows) in the palpable area of the left outer central breast. B. Ultrasonography (left, transverse view; right, longitudinal view) shows an irregular hypoechoic mass (arrows) at the palpable site. The patient had previously undergone core needle biopsy at an outside hospital for the palpable mass, and the biopsy result was fibrocystic change. This was considered a discordant benign result. Repeat ultrasound-guided 14-gauge core needle biopsy was performed, revealing invasive ductal carcinoma. recommended for repeated biopsies of discordant benign lesions at US-guided CNB, and the best biopsy method should be chosen for each case through communication between the radiologist, pathologist, referring physician, and patient.

\section{Borderline or High-Risk}

This category refers to lesions that are not malignant but are considered to indicate an increased lifetime risk of developing breast cancer, including ADH, lobular neoplasia, radial scar, papillary lesions, and possible phyllodes tumors [40]. Controversy exists regarding the appropriate surgical and oncological treatment for these lesions. These issues are beyond the scope of this article, and other published articles focus on this issue $[62,63]$. For all breast 


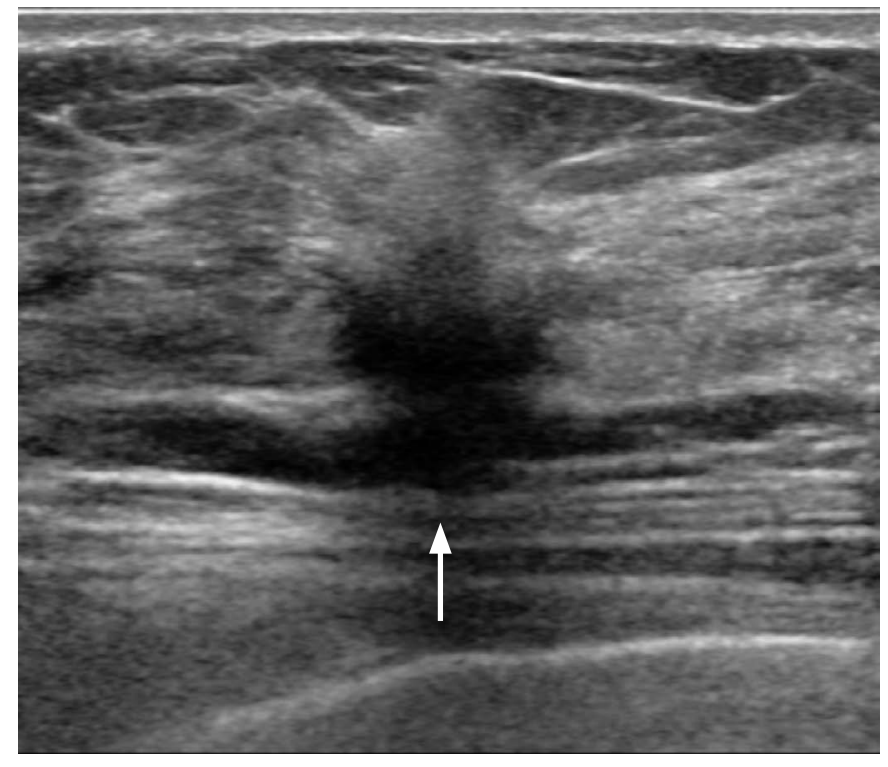

A
Fig. 9. A 43-year-old woman with a palpable mass in her right breast.

A. Transverse ultrasonography shows an irregular, non-parallel, spiculated mass (arrow) in the palpable right upper outer breast. The mass was classified as Breast Imaging Reporting and Data System category 4C. Ultrasound-guided 14-gauge core needle biopsy was performed, which obtained a pathological result of fibroadenoma with sclerosing adenosis. This was considered as a discordant benign result. B. Subsequent ultrasound-guided vacuum-assisted biopsy using a 9-gauge needle was performed, and the lesion was completely removed (left, ultrasonography during vacuum-assisted biopsy; right, ultrasonography immediately after completion of vacuum-assisted biopsy). The pathological result was sclerosing adenosis, and no newly developed lesions were observed at the biopsy site over a follow-up of more than 2 years.

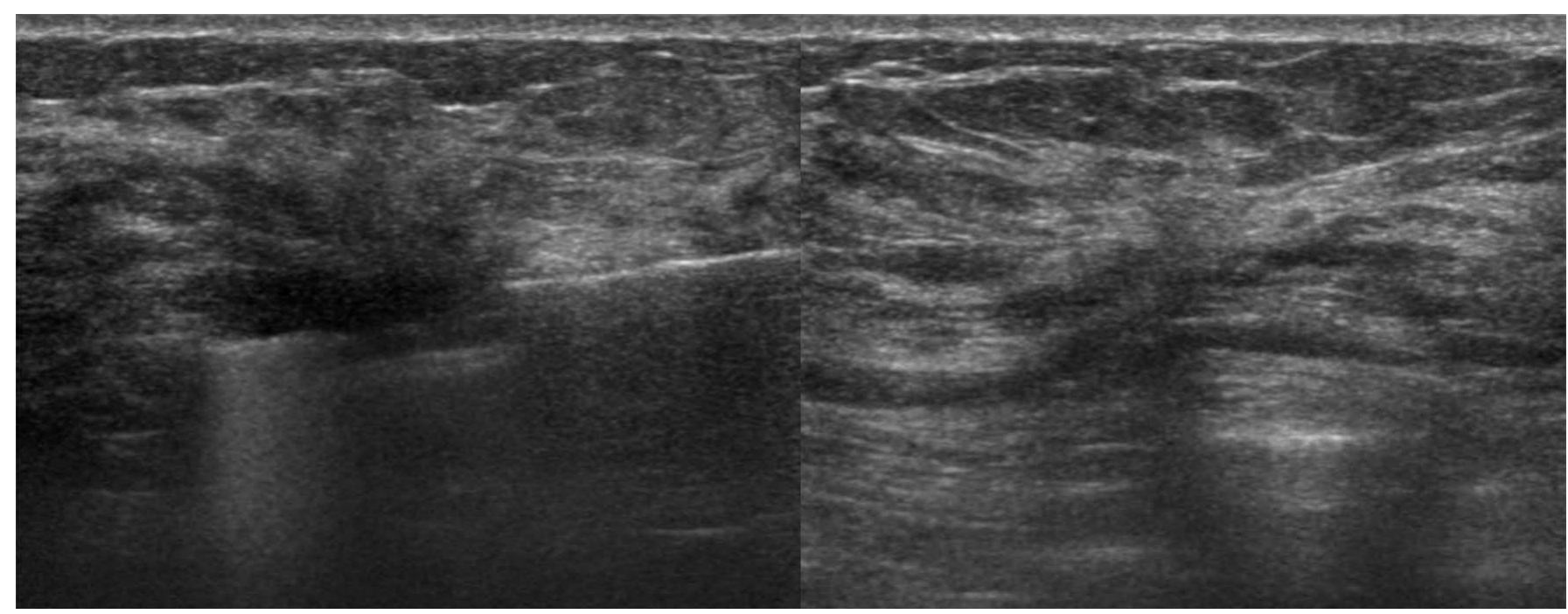

B

lesions, as with 14-gauge US-guided CNB, determining imagingpathology concordance is pivotal when performing US-guided VABB for diagnostic purposes [17]. However, its importance tends to be less emphasized when performing therapeutic US-guided VABB aiming for complete image-guided excision. However, management options have become more diverse for borderline or high-risk lesions diagnosed following US-guided VABB with complete removal, and all characteristics, including the imaging findings, should be thoroughly reviewed to recommend appropriate management. These patients should be managed by a high-risk multidisciplinary team, with active discussion and collaboration across different subspecialties [64].

Currently, active collaboration across multidisciplinary groups is making a significant difference in the management of patients with biopsy-proven high-risk lesions $[64,65]$. Most of the controversy regarding the management of such patients relates to the need for subsequent surgical excision. A thorough review and discussion of clinical and imaging findings, biopsy characteristics including the biopsy method and degree of removal, pathological findings including the extent of the lesion, and associations between clinical and pathological features and imaging can lead to personalized management recommendations $[64,66]$. For example, a diagnosis of focal ADH on pathology in a small lesion that has been nearly completely removed by vacuum-assisted biopsy may result in a recommendation of imaging follow-up [66]. In contrast, a finding of extensive high-risk disease in a lesion with limited sampling has a higher possibility of co-existing higher-grade lesions, and surgical 
excision may be recommended. Therefore, a single and unvarying approach does not seem appropriate for patients with biopsyproven high-risk breast lesions, and the management options can be individualized based on a multidisciplinary approach.

\section{Conclusion}

US-guided breast biopsy is an accurate method for diagnosing breast cancer, with a false-negative rate ranging from $0.1 \%$ to $2.5 \%$. Determining imaging-pathology concordance after USguided breast biopsy is essential, as most false-negative cases are identified because of imaging-pathology discordance. The radiologist performing the biopsy should be aware of general aspects to consider when establishing imaging-pathology concordance and the possible categories of imaging-pathology correlations. Appropriate management, including active communication with the pathologist, referring physician, and patient, should be performed accordingly.

ORCID: Vivian Youngjean Park: http://orcid.org/0000-0002-5135-4058; Eun-Kyung Kim: http://orcid.org/0000-0002-3368-5013; Hee Jung Moon: http://orcid.org/00000002-5643-5885; Jung Hyun Yoon: http://orcid.org/0000-0002-2100-3513; Min Jung Kim: http://orcid.org/0000-0003-4949-1237

\section{Conflict of Interest}

No potential conflict of interest relevant to this article was reported.

\section{Acknowledgments}

This study was supported by a faculty research grant of Yonsei University College of Medicine (6-2016-0112), by the Basic Science Research Program through the National Research Foundation of Korea (NRF) funded by the Ministry of Education (NRF2017R1D1A1B03035995), and by the Basic Science Research Program through the National Research Foundation of Korea (NRF) funded by the Ministry of Science, ICT \& Future Planning, Republic of Korea (NRF 2017R1A2B4010407).

\section{References}

1. Vandromme MJ, Umphrey $H$, Krontiras H. Image-guided methods for biopsy of suspicious breast lesions. J Surg Oncol 2011;103:299305.

2. Bae S, Yoon JH, Moon HJ, Kim MJ, Kim EK. Breast microcalcifications: diagnostic outcomes according to image-guided biopsy method. Korean J Radiol 2015;16:996-1005.

3. Uematsu T. How to choose needles and probes for ultrasonographically guided percutaneous breast biopsy: a systematic approach. Breast Cancer 2012;19:238-241.
4. Keranen AK, Haapea M, Rissanen T. Ultrasonography as a guiding method in breast micro-calcification vacuum-assisted biopsies. Ultraschall Med 2016;37:497-502.

5. Crystal P, Koretz M, Shcharynsky S, Makarov V, Strano S. Accuracy of sonographically guided 14-gauge core-needle biopsy: results of 715 consecutive breast biopsies with at least two-year follow-up of benign lesions. J Clin Ultrasound 2005;33:47-52.

6. Dillon MF, Hill AD, Quinn CM, O'Doherty A, McDermott EW, $O$ 'Higgins N. The accuracy of ultrasound, stereotactic, and clinical core biopsies in the diagnosis of breast cancer, with an analysis of false-negative cases. Ann Surg 2005;242:701-707.

7. Huang ML, Hess K, Candelaria RP, Eghtedari M, Adrada BE, Sneige $\mathrm{N}$, et al. Comparison of the accuracy of US-guided biopsy of breast masses performed with 14-gauge, 16-gauge and 18-gauge automated cutting needle biopsy devices, and review of the literature. Eur Radiol 2017;27:2928-2933.

8. Schueller G, Jaromi S, Ponhold L, Fuchsjaeger M, Memarsadeghi $M$, Rudas $M$, et al. US-guided 14-gauge core-needle breast biopsy: results of a validation study in 1352 cases. Radiology 2008:248:406-413.

9. Youk JH, Kim EK, Kim MJ, Kwak JY, Son EJ. Analysis of falsenegative results after US-guided 14-gauge core needle breast biopsy. Eur Radiol 2010;20:782-789.

10. Youk JH, Kim EK, Kim MJ, Oh KK. Sonographically guided 14-gauge core needle biopsy of breast masses: a review of 2,420 cases with long-term follow-up. AJR Am J Roentgenol 2008;190:202-207.

11. Zhang $C$, Lewis DR, Nasute $P$, Hayes M, Warren LJ, Gordon PB. The negative predictive value of ultrasound-guided 14-gauge core needle biopsy of breast masses: a validation study of 339 cases Cancer Imaging 2012;12:488-496

12. Roberts JG, Preece PE, Bolton PM, Baum M, Hughes LE. The 'trucut' biopsy in breast cancer. Clin Oncol 1975;1:297-303.

13. Parker SH, Jobe WE, Dennis MA, Stavros AT, Johnson KK, Yakes WF, et al. US-guided automated large-core breast biopsy. Radiology 1993;187:507-511.

14. Jung I, Kim MJ, Moon HJ, Yoon JH, Kim EK. Ultrasonography-guided 14-gauge core biopsy of the breast: results of 7 years of experience. Ultrasonography 2018;37:55-62.

15. Jung HK, Moon HJ, Kim MJ, Kim EK. Benign core biopsy of probably benign breast lesions $2 \mathrm{~cm}$ or larger: correlation with excisional biopsy and long-term follow-up. Ultrasonography 2014;33:200205.

16. Jang $M$, Cho N, Moon WK, Park JS, Seong MH, Park IA. Underestimation of atypical ductal hyperplasia at sonographically guided core biopsy of the breast. AJR Am J Roentgenol 2008;191:13471351.

17. Hahn M, Krainick-Strobel U, Toellner T, Gissler J, Kluge S, Krapfl E et al. Interdisciplinary consensus recommendations for the use of vacuum-assisted breast biopsy under sonographic guidance: first 
update 2012. Ultraschall Med 2012;33:366-371.

18. Cassano E, Urban LA, Pizzamiglio M, Abbate $F$, Maisonneuve $P$, Renne $G$, et al. Ultrasound-guided vacuum-assisted core breast biopsy: experience with 406 cases. Breast Cancer Res Treat 2007;102:103-110.

19. Grady I, Gorsuch H, Wilburn-Bailey S. Ultrasound-guided, vacuumassisted, percutaneous excision of breast lesions: an accurate technique in the diagnosis of atypical ductal hyperplasia. J Am Coll Surg 2005;201:14-17.

20. Lee SH, Kim EK, Kim MJ, Moon HJ, Yoon JH. Vacuum-assisted breast biopsy under ultrasonographic guidance: analysis of a 10-year experience. Ultrasonography 2014;33:259-266.

21. Cho N, Moon WK, Cha JH, Kim SM, Kim SJ, Lee SH, et al. Sonographically guided core biopsy of the breast: comparison of 14-gauge automated gun and 11-gauge directional vacuumassisted biopsy methods. Korean J Radiol 2005;6:102-109.

22. Simon JR, Kalbhen CL, Cooper RA, Flisak ME. Accuracy and complication rates of US-guided vacuum-assisted core breast biopsy: initial results. Radiology 2000;215:694-697.

23. Philpotts LE, Hooley RJ, Lee CH. Comparison of automated versus vacuum-assisted biopsy methods for sonographically guided core biopsy of the breast. AJR Am J Roentgenol 2003;180:347-351.

24. Youk JH, Kim EK, Kim MJ, Lee JY, Oh KK. Missed breast cancers at US-guided core needle biopsy: how to reduce them. Radiographics 2007;27:79-94.

25. Fishman JE, Milikowski C, Ramsinghani R, Velasquez MV, Aviram G. US-guided core-needle biopsy of the breast: how many specimens are necessary? Radiology 2003;226:779-782.

26. Wu YC, Chen DR, Kuo SJ. Personal experience of ultrasoundguided 14-gauge core biopsy of breast tumor. Eur I Surg Oncol 2006;32:715-718.

27. Cho N, Moon WK, Cha JH, Kim SM, Jang M, Chang JM, et al. Ultrasound-guided vacuum-assisted biopsy of microcalcifications detected at screening mammography. Acta Radiol 2009;50:602609.

28. Uematsu T, Kasami M, Uchida Y, Yuen S, Sanuki J, Kimura K, et al. Ultrasonographically guided 18-gauge automated core needle breast biopsy with post-fire needle position verification (PNPV). Breast Cancer 2007;14:219-228.

29. Lazarus E, Mainiero MB, Schepps B, Koelliker SL, Livingston LS. BIRADS lexicon for US and mammography: interobserver variability and positive predictive value. Radiology 2006;239:385-391.

30. Kim EK, Ko KH, Oh KK, Kwak JY, You JK, Kim MJ, et al. Clinical application of the BI-RADS final assessment to breast sonography in conjunction with mammography. AJR Am J Roentgenol 2008;190:1209-1215.

31. Lee HJ, Kim EK, Kim MJ, Youk JH, Lee JY, Kang DR, et al. Observer variability of Breast Imaging Reporting and Data System (BI-RADS) for breast ultrasound. Eur J Radiol 2008;65:293-298.
32. Mendelson EB, Bohm-Velez M, Berg WA, Whitman GJ, Feldman MI, Madjar $\mathrm{H}$, et al. ACR BI-RADS ultrasound. In: D'Orsi CJ, Sickles EA, Mendelson EB, Morris EA, eds. ACR BI-RADS Atlas, Breast Imaging Reporting and Data System. 5th ed. Reston, VA: American College of Radiology, 2013;1-173.

33. Youk JH, Kim EK, Kim MJ, Ko KH, Kwak JY, Son EJ, et al. Concordant or discordant? Imaging-pathology correlation in a sonographyguided core needle biopsy of a breast lesion. Korean J Radiol 2011;12:232-240.

34. Yoon JH, Kim MJ, Moon HJ, Kwak JY, Kim EK. Subcategorization of ultrasonographic BI-RADS category 4: positive predictive value and clinical factors affecting it. Ultrasound Med Biol 2011;37:693-699.

35. Park CS, Lee JH, Yim HW, Kang BJ, Kim HS, Jung Jl, et al. Observer agreement using the ACR Breast Imaging Reporting and Data System (BI-RADS)-ultrasound, First Edition (2003). Korean J Radiol 2007;8:397-402.

36. Abdullah N, Mesurolle B, El-Khoury M, Kao E. Breast imaging reporting and data system lexicon for US: interobserver agreement for assessment of breast masses. Radiology 2009;252:665-672.

37. Mihalik JE, Krupka L, Davenport R, Tucker L, Toevs C, Smith RS. The rate of imaging-histologic discordance of benign breast disease: a multidisciplinary approach to the management of discordance at a large university-based hospital. Am J Surg 2010;199:319-323.

38. Monticciolo DL, Hajdik RL, Hicks MG, Winford JK, Larkin WR, Vasek $\mathrm{JV} \mathrm{jr}$, et al. Six-month short-interval imaging follow-up for benign concordant core needle biopsy of the breast: outcomes in 1444 cases with long-term follow-up. AJR Am J Roentgenol 2016 Jun 24 [Epub]. https://doi.org/10.2214/AJR.15.15853.

39. Salkowski LR, Fowler AM, Burnside ES, Sisney GA. Utility of 6-month follow-up imaging after a concordant benign breast biopsy result. Radiology 2011;258:380-387.

40. Parikh J, Tickman R. Image-guided tissue sampling: where radiology meets pathology. Breast J 2005;11:403-409.

41. Yoo JL, Woo OH, Kim YK, Cho KR, Yong HS, Seo BK, et al. Can MR Imaging contribute in characterizing well-circumscribed breast carcinomas? Radiographics 2010;30:1689-1702.

42. Song SE, Cho N, Chu A, Shin SU, Yi A, Lee SH, et al. Undiagnosed breast cancer: features at supplemental screening US. Radiology 2015;277:372-380.

43. Moon HJ, Jung I, Youk JH, Kim MJ, Kim EK. Short-term follow-up in 6 months is unnecessary for asymptomatic breast lesions with benign concordant results obtained at ultrasonography-guided 14-gauge core needle biopsy. Am J Surg 2016;211:152-158.

44. Sickles EA, Ominsky SH, Sollitto RA, Galvin HB, Monticciolo DL. Medical audit of a rapid-throughput mammography screening practice: methodology and results of 27,114 examinations. Radiology 1990;175:323-327.

45. March DE, Raslavicus A, Coughlin BF, Klein SV, Makari-Judson G. Use of breast core biopsy in the United States: results of a national 
survey. AJR Am J Roentgenol 1997;169:697-701.

46. Shin S, Schneider HB, Cole FJ Jr, Laronga C. Follow-up recommendations for benign breast biopsies. Breast J 2006;12:413-417.

47. Lee $\mathrm{CH}$, Philpotts LE, Horvath LJ, Tocino I. Follow-up of breast lesions diagnosed as benign with stereotactic core-needle biopsy: frequency of mammographic change and false-negative rate. Radiology 1999;212:189-194.

48. Schoonjans JM, Brem RF. Fourteen-gauge ultrasonographically guided large-core needle biopsy of breast masses. J Ultrasound Med 2001;20:967-972.

49. Youk JH, Jung I, Kim EK, Kim MJ, Son EJ, Moon HJ, et al. US followup protocol in concordant benign result after US-guided 14-gauge core needle breast biopsy. Breast Cancer Res Treat 2012;132:10891097.

50. Adams MC, Falcon S, Mooney BP, Laronga C, Chau A, Drukteinis JS. Short-term imaging follow-up of patients with concordant benign breast core needle biopsies: is it really worth it? Diagn Interv Radiol 2014;20:464-469.

51. Manjoros DT, Collett AE, Alberty-Oller JJ, Frazier TG, Barrio AV. The value of 6-month interval imaging after benign radiologicpathologic concordant minimally invasive breast biopsy. Ann Surg Oncol 2013;20:3163-3168.

52. Mateo AM, Frankel AM. Is 6-month radiologic imaging necessary after benign breast biopsy? Review of literature and multicenter experience. Am Surg 2015;81:1224-1227.

53. Plecha DM, Garlick C, Dubchuck C, Thompson C, Constantinou N. Comparing cancer detection rates of patients undergoing short term follow-up vs routine follow-up after benign breast biopsies, is follow-up needed? Clin Imaging 2017;42:37-42.

54. Kim MJ, Kim EK, Lee JY, Youk JH, Park BW, Kim SI, et al. Breast lesions with imaging-histologic discordance during US-guided 14G automated core biopsy: can the directional vacuum-assisted removal replace the surgical excision? Initial findings. Eur Radiol 2007; 17:2376-2383.

55. Son EJ, Kim EK, Youk JH, Kim MJ, Kwak JY, Choi SH. Imaginghistologic discordance after sonographically guided percutaneous breast biopsy: a prospective observational study. Ultrasound Med Biol 2011;37:1771-1778.
56. Soyder A, Taskin F, Ozbas S. Imaging-histological discordance after sonographically guided percutaneous breast core biopsy. Breast Care (Basel) 2015;10:33-37.

57. Cho SH, Park SH. Mimickers of breast malignancy on breast sonography. J Ultrasound Med 2013;32:2029-2036.

58. Kim MJ, Kim D, Jung W, Koo JS. Histological analysis of benign breast imaging reporting and data system categories $4 \mathrm{c}$ and 5 breast lesions in imaging study. Yonsei Med J 2012;53:1203-1210.

59. Li JL, Wang ZL, Su L, Liu XJ, Tang J. Breast lesions with ultrasound imaging-histologic discordance at 16-gauge core needle biopsy: can re-biopsy with 10-gauge vacuum-assisted system get definitive diagnosis? Breast 2010;19:446-449.

60. Wang ZL, Liu G, Li JL, Su L, Liu XJ, Wang W, et al. Breast lesions with imaging-histologic discordance during 16-gauge core needle biopsy system: would vacuum-assisted removal get significantly more definitive histologic diagnosis than vacuum-assisted biopsy? Breast J 2011;17:456-461.

61. Sohn YM, Yoon JH, Kim EK, Moon HJ, Kim MJ. Percutaneous ultrasound-guided vacuum-assisted removal versus surgery for breast lesions showing imaging-histology discordance after ultrasound-guided core-needle biopsy. Korean J Radiol 2014; 15:697-703.

62. Georgian-Smith D, Lawton TJ. Controversies on the management of high-risk lesions at core biopsy from a radiology/pathology perspective. Radiol Clin North Am 2010;48:999-1012.

63. Degnim AC, King TA. Surgical management of high-risk breast lesions. Surg Clin North Am 2013;93:329-340.

64. Krishnamurthy $S$, Bevers T, Kuerer $H$, Yang WT. Multidisciplinary considerations in the management of high-risk breast lesions. AJR Am J Roentgenol 2012;198:W132-W140.

65. Middleton LP, Sneige N, Coyne R, Shen Y, Dong W, Dempsey P, et al. Most lobular carcinoma in situ and atypical lobular hyperplasia diagnosed on core needle biopsy can be managed clinically with radiologic follow-up in a multidisciplinary setting. Cancer Med 2014;3:492-499.

66. Krishnamurthy S, Bevers T, Kuerer HM, Smith B, Yang WT. Paradigm shifts in breast care delivery: impact of imaging in a multidisciplinary environment. AJR Am J Roentgenol 2017;208:248-255. 